39.P12

\title{
Free Floating Microcultures of Human Fetal Ventral Mesencephalon
}

\author{
C. Spenger, C. Hyman*, L. Studer, L. Hotayt and R.W. Seiler \\ Department of Neurosurgery, University Hospital of Bern, Inselspital, CH-3010 Bern, Switzerland; \\ *Regeneron Pharmaceutical Inc., Tarrytown, N.Y., USA
}

In the reported clinical trials of human fetal ventral mesencephalic transplants to the brain of Parkinson patients the tissue was transplanted either as small solid pieces or as cell suspensions. In all cases the tissues were implanted immediately after explantation. Delayed surgery and the in vitro maintenance of the tissue prior to transplantation would present several advantages. For example, this would allow one to estimate the approximate number of neurons transplanted and to measure dopamine content and tyrosine-hydroxylase ( $\mathrm{TH})$ activity in vitro expressing the activity of the cultures. Furthermore tissues in vitro could be treated with various growth factors.

Here we present a protocol to maintain human fetal ventral mesencephalic tissue in free floating microcultures. Ventral mesencephalon of human fetuses was obtained from material of induced suction abortions. Out of 38 abortions the mesencephalon could be identified in 16 cases $(50 \%$ in fetuses age 8-10 weeks post mens. and $31 \%$ in fetuses age $11-13$ weeks post mens.) based on macroscopic criteria. The landmarks which allowed identification were first the isthmus rhombencephali and second the IV ventricle (caudal to the mesencephalon) and the recessus ventriculi III (rostral to the mesencephalon) as well as the mesencephalic flexure. However the tissue was most often fractured at the isthmus.

The ventral mesencephalon was dissected out of the identified brain tissue and divided into four longitudinal pieces. These pieces were transversely chopped in $250 \mu \mathrm{m}$ steps by means of a tissue chopper (McIllwain). These tissue pieces (one piece per tube) were transferred into plastic tubes (Falcon No. 2095) (one culture per tube) containing $1 \mathrm{ml}$ of medium. One hun- dred $\mathrm{ml}$ of medium consisted of $55 \mathrm{ml}$ Dulbecco MEM (Gibco No. 041-02320), 32.5 ml Hanks BSS (Gibco No. 041-04020), $1.5 \mathrm{ml}$ glucose 20\%, $10 \mathrm{ml} \mathrm{FCS} \mathrm{(Gibco} \mathrm{No.} \mathrm{013-06290),} \mathrm{and} 1 \mathrm{ml}$ of 23.8\% HEPES. A triple-antibiotic (Gibco No. 043-05240D) was used during the first 4 days in vitro. Ten $\mathrm{ng} / \mathrm{ml} \mathrm{NGF,} 10 \mathrm{ng} / \mathrm{ml} \mathrm{BDNF}$ or 10 $\mathrm{ng} / \mathrm{ml} \mathrm{bFGF}$ was added to the medium. The tubes were placed in a revolving drum (60 revolutions per hour) in an incubator with $5 \%$ $\mathrm{CO}_{2}$. The medium was changed at 3 and 4 day intervals. After 5-14 days in vitro, these cultures were pooled in groups of 5-10 cultures and processed for electron microscopy, histology in frozen sections or enzyme and transmitter assays.

The cultures survived and developed further in vitro. After 5 days in vitro, the tissue pieces had turned into small round balls of 0.5 to $1 \mathrm{~mm}$ in diameter. Histological examinations of mesencephalic cultures showed good survival of the tissue. $\mathrm{TH}$ positive cells were demonstrated by immunohistochemistry and dopamine and tyrosine hydroxylase was detected in biochemical assays. When free floating microcultures were explanted onto coverslips after 14 days in vitro and grown by the roller tube method for one week, newly formed processes extended from the explant.

These experiments show the feasibility of maintaining human fetal ventral mesencephalon in vitro by means of free floating microcultures. It is suggested that the transplantation of these cultures be tested in rats as a next step.

Supported by the Swiss National Science Foundation No. 31-32561.91 and the Swiss Parkinson Society. BDNF was kindly supplied by Regeneron Pharmaceutical Inc., N.Y., USA. 

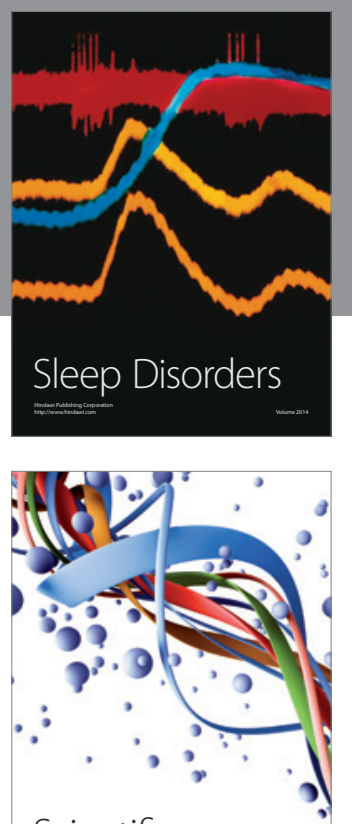

Scientifica
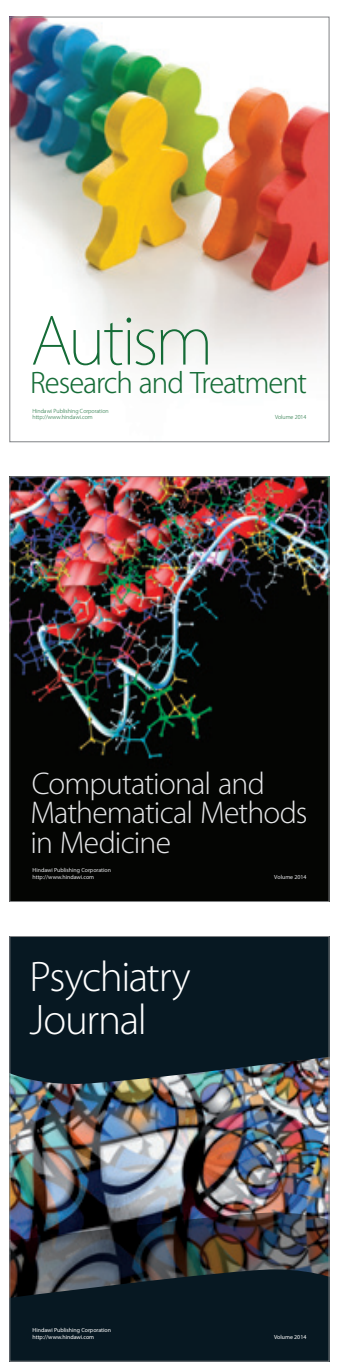
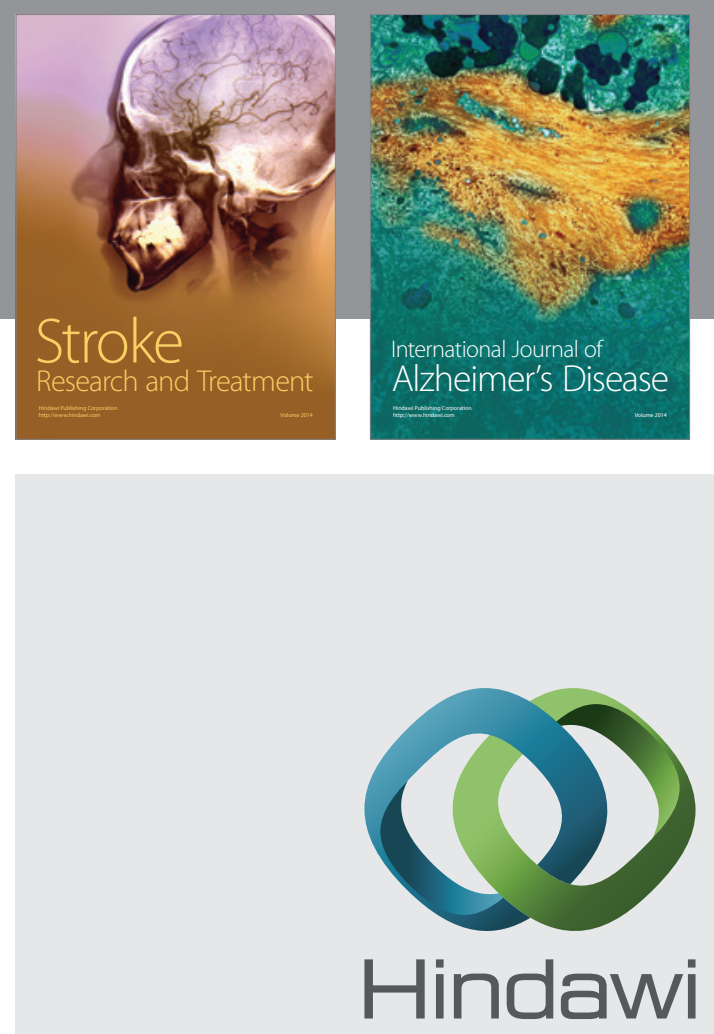

Submit your manuscripts at

http://www.hindawi.com
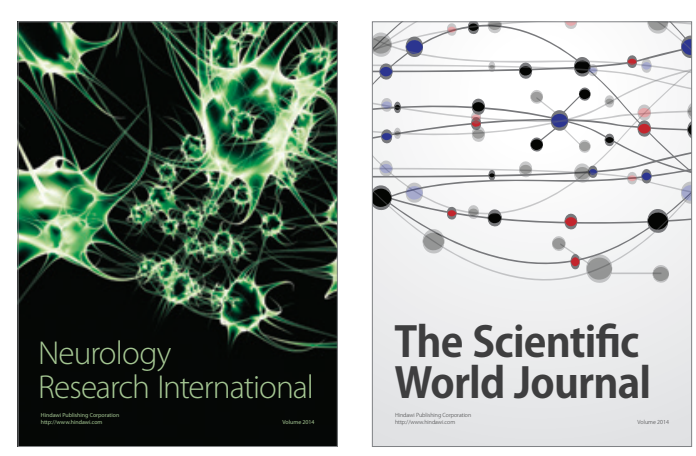

The Scientific World Journal

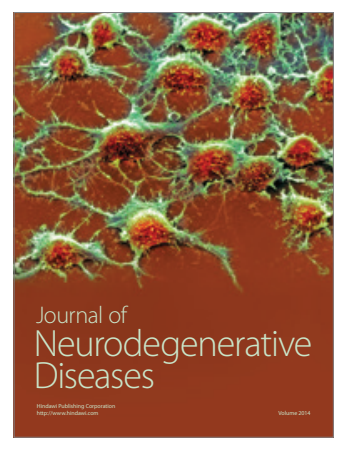

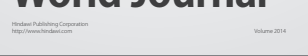

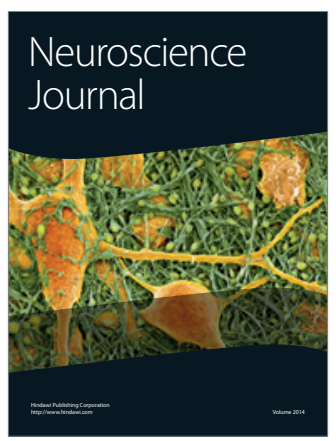

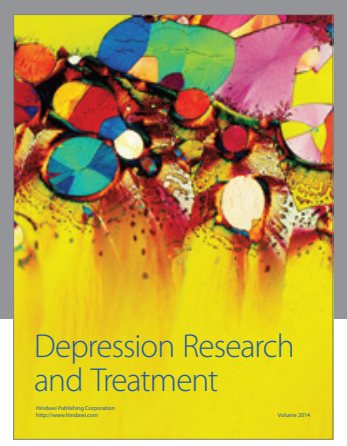
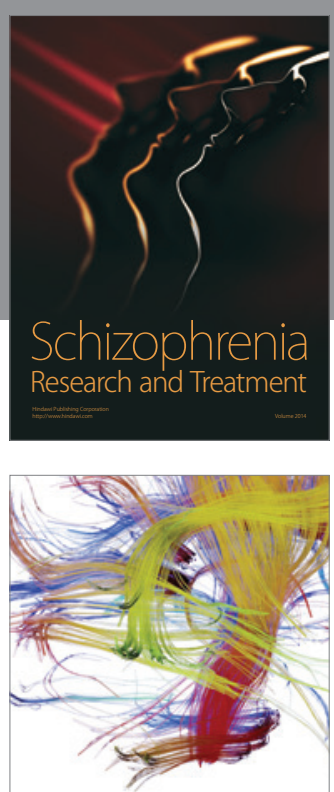

Brain Science

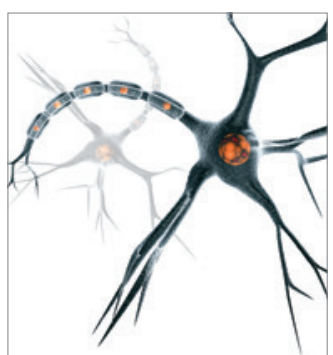

Neural Plasticity
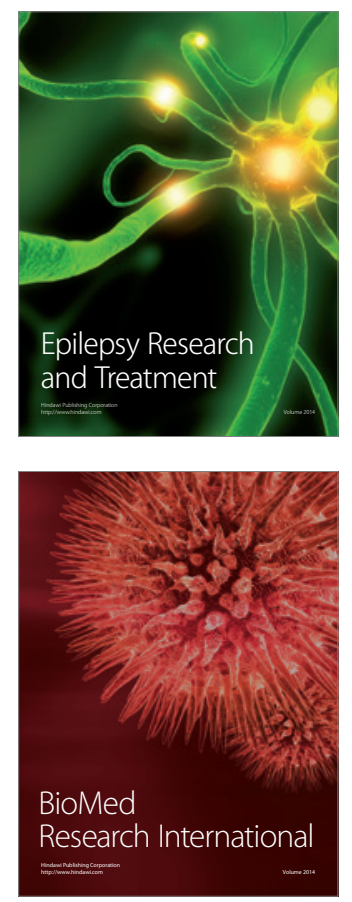

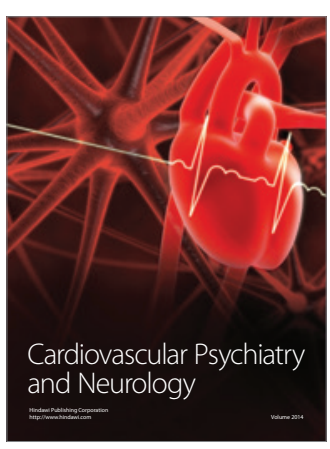

Parkinson's

Disease
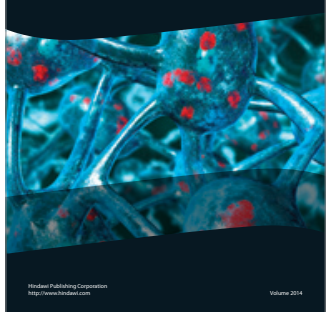